\title{
Measures of a Sustainable Commute as a Predictor of Happiness
}

\author{
Scott Cloutier ${ }^{1, *}$ (D), Alex Karner ${ }^{2}$, Hanna L. Breetz ${ }^{1}$, Parinaz Toufani ${ }^{3}$, Nuri Onat ${ }^{3}$, \\ Sambhram Patel ${ }^{1}$ (D), Siddhanth Paralkar ${ }^{1}$, Erica Berejnoi ${ }^{1}$, Beth Ann Morrison ${ }^{1}$ (D), \\ Jason Papenfuss ${ }^{1}$, A. Davieau Briggs ${ }^{1}$ and Cynthia Carlson ${ }^{4}$ \\ 1 Julie Ann Wrigley Global Institute of Sustainability, School of Sustainability, Arizona State University, \\ Tempe, AZ 85281, USA; hbreetz@asu.edu (H.L.B.); sambhram.patel@asu.edu (S.P.); \\ siddhanth.paralkar@asu.edu (S.P.); Erica.Berejnoibejarano@asu.edu (E.B.); \\ bethann.morrison@asu.edu (B.A.M.); jason.papenfuss@asu.edu (J.P.); davi.briggs@asu.edu (A.D.B.) \\ 2 Graduate Program in Community and Regional Planning, School of Architecture, \\ University of Texas at Austin, Austin, TX 78712, USA; alex.karner@utexas.edu \\ 3 Department of Industrial Engineering at Istanbul Sehir University, 34865 Istanbul, Turkey; \\ parinaztoufani@std.sehir.edu.tr (P.T.); nurionat@sehir.edu.tr (N.O.) \\ 4 Department of Civil Engineering, Merrimack College, North Andover, MA 01845, USA; \\ cyndycarlson@gmail.com \\ * Correspondence: scott.cloutier@asu.edu; Tel.: +1-480-965-5029
}

Received: 2 June 2017; Accepted: 7 July 2017; Published: 13 July 2017

\begin{abstract}
The ways in which we travel—by what mode, for how long, and for what purpose-can affect our sense of happiness and well-being. This paper assesses the relationships between measures of the sustainability of transportation systems in U.S. metropolitan areas and subjective well-being. Associations between self-reported happiness levels from the Gallup Healthways Well-being Index and commute data were examined for 187 core-based statistical areas (CBSA). We also supplement this quantitative analysis through brief case studies of high- and low-performing happiness cities. Our quantitative results indicate that regions with higher commute mode shares by non-automobile modes generally had higher well-being scores, even when controlling for important economic predictors of happiness. We also find that pro-sustainable transportation policies can have implications for population-wide happiness and well-being. Our case studies indicate that both high and low scoring happiness cities demonstrate a dedicated commitment to improving sustainable transportation infrastructure. Our study suggests that cities that provide incentives for residents to use more sustainable commute modes may offer greater opportunity for happiness than those that do not.
\end{abstract}

Keywords: happiness; subjective well-being; sustainability; transportation; sustainable transportation

\section{Introduction}

Cities and regions serve as hubs of production, distribution, and consumption of both material (e.g., land, buildings) and non-material goods and services (e.g., services of doctors, education), thereby providing economic, environmental, social, and cultural opportunities for their residents. Because these opportunities within regions are spatially diffuse, safe and efficient mobility is essential. Infrastructure that supports the use of both motorized and non-motorized modes can provide opportunities to incorporate physical activity into daily routines, and may improve subjective well-being (SWB) or happiness [1-3]. In short, a region's transportation infrastructure may enhance quality of life, well-being, and happiness by offering a variety of transportation choices. Therefore, it is important that we understand the urban transportation factors that affect regional quality of life, as reported 
through subjective well-being (SWB). Relevant academic studies can inform the design and retrofit of our future cities and neighborhoods to promote both a happy and sustainable future.

The goal of this study is to understand the link between commute indicators and SWB in metropolitan areas in the United States. Associations between commute modes from the American Community Survey and self-reported core based statistical area (CBSA) happiness data from the Gallup Healthways Well-being Index [4], and commute characteristics are examined. In particular, we analyze the extent to which measures of a sustainable commute are associated with SWB. We hypothesize that the use of sustainable commute modes will be associated with regional SWB. In addition to examining this hypothesis, this study aims to identify potential transportation management strategies that may offer residents greater opportunities to pursue their own happiness (as a result of greater regional happiness opportunities) through case studies of high- and low-performing happiness cities. Further, we discuss an agenda for future in-depth studies, looking closely at happiness, as influenced by aspects of the transportation system.

\section{Literature Review}

Projections indicate that nearly three quarters of the world's population will live in cities by the year 2050 [5]. In response, urban sustainability has become a key focus for the future. During the September 2015 United Nations Sustainable Development Summit, world leaders agreed to making cities inclusive, safe, resilient, and sustainable, while also ensuring good health and well-being [6]. We suggest that sustainable cities and well-being can be mutually inclusive. In fact, two years prior to the UN Development Summit, Montgomery [7] described the city as an eternal happiness experiment, while researchers have been exploring connections between happiness and urban spaces [8-11].

Accordingly, more studies are needed to understand how cities and their transportation systems affect human well-being and happiness. Happiness is a relatively new addition to the lexicon of planning and community development [12-14]. Planners, architects, community developers, and scientists are discovering that transportation systems influence happiness [15-19]. Transportation networks facilitate access to destinations that are vitally important to maintaining or enhancing modern life and SWB [20,21], and the ways in which we travel—by what mode, for how long, and for what purpose-can affect our sense of happiness [3,12].

\subsection{Transportation Mode}

Research indicates that the modes by which humans commute have an impact on our happiness levels. Automobile use has been found to increase negative consequences such as boredom, social isolation, and stress [22]. Commuters who walk and bicycle have significantly higher self-reported happiness levels than those who drive, even when accounting for differences in income, health, and attitudes about travel [23]. Physically active modes of commuting, like cycling, have also been shown to reduce the number of sickness incidences over time [24]. Moreover, bicycle and pedestrian commuters self-report improved health, lower exhaustion and stress levels, and fewer missed workdays than their counterpart automobile commuters [25].

The positive sensations derived from walking and cycling support the notion that exercise improves mood, thereby beginning and ending one's workday in a stress-reducing manner, contributing to physiological and psychological wellness [26]. Another alternative commute mode, telecommuting, or working from home, can also be an effective tool to improve commuter happiness [27,28]. Telecommuting promotes personal well-being by increasing perceived control over time [29] and reducing job-related negative effects on well-being as compared to days working in the office [30].

\subsection{Commute Experience}

While mode choice is important to SWB, other aspects of the commuting experience, including the magnitude of typically encountered congestion and distance, are also associated with happiness 
impacts [2]. For example, the longer our commute, the more likely it is that we will be unhappy $[17,31,32]$. Additionally, people who drive for long periods of time are likely to become sedentary [33], stressed, or bored [17]. Sedentary lifestyles result in lower overall well-being and have been linked to an increased risk of cancer, stroke, and depression [34]. Ettema et al. [15] found that satisfaction with travel is correlated with experienced traffic safety, annoyance with road users, the trip being tiring, being distracted by billboards, and a lack of freedom to choose speed and lane.

\subsection{Transportation Infrastructure}

The nature of the built environment also influences commuter mode choice and experience. Built environment characteristics, such as high residential densities and enhanced walkability via street connectivity, are associated with higher levels of physical activity and reductions in obesity [35]. Both adolescents and aging populations have experienced higher levels of psychological well-being in walkable neighborhoods [36,37]. In some instances, transportation infrastructure placement causes inequitable psychological or physical barriers to local amenities like parks and shops. This promotes personal automobile use in place of more sustainable transportation [38], potentially lowering well-being levels.

Despite the link between activity, accessibility, and happiness, transportation planners have not historically considered SWB, and have instead focused on addressing other more easily measured factors including travel time, level of service, and congestion. While there are inherent connections between these factors and SWB, focusing on them alone may neglect transportation impacts on people that are more challenging to measure or monetize, including SWB [26]. A focus on transportation systems and happiness could have enormous benefits at the individual and community levels, as increases in happiness have been connected to marked increases in health, productivity, and sustainability [13]. In general, the literature supports the notion that sustainable modes that reduce the onerousness of the commute or combine it with enjoyable activities like exercise may lead to greater happiness.

\section{Data and Methods}

As in Cloutier et al. [8], this paper treats happiness and well-being as synonyms. Happiness scores were obtained for 2009-the only year of freely available data-from the Gallup Healthways Well-Being Index (WBI) [4] for 187 Core Based Statistical Areas (CBSAs) across the United States. Any data beyond the 2009 data set requires a significant access fee. While we acknowledge that 187 does not represent the total population of CBSAs in the United States ( $\mathrm{n}$ 1000), it does include the total number of observed CBSAs for which happiness data are complete. Our study is not meant to be representative of all CBSAs, rather, we highlight the links between happiness and sustainable transportation modes for those CBSAs with complete observations. The CBSAs were sampled by Gallup to reach a minimum number of respondents to represent the local population. CBSAs are defined by the US Office of Management and Budget (OMB), and include both metropolitan (urban core with population $>50,000$ ) and micropolitan (urban core with population between 10,000 and $50,000)$ statistical areas [39]. CBSAs are meant to define regions that have substantial economic ties across counties as measured by commute behavior. We chose CBSAs as the units of analysis, as opposed to states, congressional districts, or census tracts, because of this explicit link to commuting behavior and because other characteristics of a region are likely to affect self-reported measures of well-being (e.g., congestion levels, transit availability, urban form, etc.). Regional governments are also responsible for overseeing the allocation of large portions of federal transportation dollars, and wield important influence over transportation policy and planning [40,41].

Gallup collects WBI data by interviewing U.S. adults aged 18 and older living in all 50 states and the District of Columbia using a dual-frame design, which includes both landline and cellphone numbers (each category makes up half the population sample). More information on Gallup's sampling 
protocol is available online [4]. The WBI includes an overall index score based on five essential elements [42]:

(1) Physical well-being refers to having good health and enough energy to get things done on a daily basis (it encompasses both physical and mental health domains that are sustained through healthy living habits);

(2) Community well-being is about the sense of engagement individuals have with the area where they live (it refers to feelings of safety, security, and sense of local pride);

(3) Social well-being is about having strong relationships and love in life, accounting for the interactions and social connections that make life more enjoyable;

(4) Financial well-being is about effectively managing one's economic life by fostering a sense of economic security and an ability to fulfill essential needs;

(5) Purpose and associated career well-being center on how one occupies his or her time and the enjoyment of daily activities (it fosters enthusiasm about the future and a sense of self-worth that leads to fulfillment).

Although the WBI is designed to produce a composite well-being score ranging from 0 to 100 , it also produces individual scores for each of the five distinct elements of well-being that can be independently analyzed [4]. The WBI has been used in studies comparing well-being and happiness to economic, environmental, and social factors [43-45]. Additionally, Gallup releases an annual report on the state of well-being in cities, states, and the United States [4].

The authors paired 1-year estimates from the American Community Survey (ACS) with the well-being data from 2009, for sustainable commute measures and other variables likely to influence happiness. These were also collected at the CBSA scale to match the geography of the dependent variable. Using ACS microdata for this purpose would not be appropriate because all of the residents of a region would be assigned the same WBI score. Instead, we are conducting an ecological study of variation in SWB across CBSAs.

Table 1 shows the descriptive statistics for the data used in this study. For control variables, we drew on prior studies investigating and describing the challenges of predicting happiness relationships using aggregate data. We first drew on studies associating individual happiness with macroeconomic measures, like region-wide household income [46-48], percentages of renting and homeownership [49], and aggregate unemployment [50], as utility levels are impacted. Clark et al. [51] found that regional unemployment impacts the happiness of the employed over concerns of limited job security. Even when in work, people fear unemployment, and when it goes up, happiness is affected for both the employed and unemployed [52]. For our study, we assume that measures of median income and regional unemployment can have both positive and negative implications for happiness, but we are interested in the overall trend of the combined CBSAs as related to regional happiness. Prior studies also indicate aggregate measures of age [9,46,53], education levels [54], immigration levels [55], and access to healthcare [56] to be determinants of individual happiness. Similarly, regional disability rates have been found to correlate with levels of happiness, particularly when the disability is most likely to affect work outcome [32]. Thus, for our study, region-wide household income, unemployment rate, median age, proportion with greater than a high school education, proportion foreign-born, proportion disabled, proportion renting, and proportion with health insurance coverage were included specifically to control for the important effects of these variables on happiness. Not captured in the table is the multicollinearity that exists between the mode share measures. This is expected, since places that are conducive to driving will generally have low rates of walking, cycling, and public transit use. This is confirmed by negative, substantively large but statistically insignificant (i.e., $p>0.05$ ), correlation coefficients between drive alone proportion and carpool, non-motorized, public transit, and telecommuting shares. Non-motorized mode share was correlated with telecommuting and public transit mode shares. These results were also substantively large but statistically insignificant. Because of these relationships, it was not possible-or desirable - to enter all of these variables into the model 
simultaneously. Because of the inherent interdependence of the mode share variables, interpreting them in an "all else equal" manner is simply not useful, since shifts in one variable will necessarily entail shifts in the others.

Table 1. Descriptive statistics for all variables.

\begin{tabular}{|c|c|c|c|c|}
\hline Research Variables & Minimum & Maximum & Mean & Standard Deviation \\
\hline \multicolumn{5}{|c|}{ Dependent Variable } \\
\hline Composite Gallup-Healthways Well-being Index & 59.5 & 72.5 & 65.92 & 2.10 \\
\hline \multicolumn{5}{|c|}{ Independent Variables } \\
\hline Median household income & $\$ 30,460$ & $\$ 85,168$ & $\$ 50,954$ & $\$ 9238$ \\
\hline Unemployment rate & 0.05 & 0.16 & 0.10 & 0.02 \\
\hline Median age & 23.3 & 48.9 & 36.91 & 3.82 \\
\hline Proportion foreign-born & 0.01 & 0.37 & 0.10 & 0.07 \\
\hline Proportion with greater than a high school education & 0.61 & 0.94 & 0.86 & 0.05 \\
\hline Proportion disabled & 0.06 & 0.21 & 0.12 & 0.02 \\
\hline Proportion renting & 0.19 & 0.49 & 0.33 & 0.05 \\
\hline Proportion with health insurance coverage & 0.64 & 0.96 & 0.86 & 0.05 \\
\hline Mean commute time (min) & 17.43 & 34.57 & 23.18 & 3.18 \\
\hline \multicolumn{5}{|c|}{ Commute Mode Share } \\
\hline Drive alone proportion & 0.50 & 0.87 & 0.79 & 0.05 \\
\hline Telecommute proportion & 0.02 & 0.12 & 0.04 & 0.01 \\
\hline Carpool proportion & 0.06 & 0.17 & 0.10 & 0.02 \\
\hline Public transportation proportion (all modes) & 0.00 & 0.30 & 0.02 & 0.03 \\
\hline Non-motorized proportion & 0.01 & 0.10 & 0.03 & 0.02 \\
\hline
\end{tabular}

Rather than undertake exploratory modeling to determine one "best" model, we sought to understand how well-being was related to the use of each mode across all regions. We therefore estimated a series of regression models, one for each mode, while including the economic control variables. An initial investigation of the univariate distributions indicated that median income and median age were right skewed. We log transformed them for subsequent analysis. Because of the substantially higher transit and non-motorized levels of service and corresponding mode shares in the New York CBSA relative to the rest of the country, that region was removed from subsequent analyses. Separate analyses of residuals versus predicted values and each independent variable indicated no systematic issues with model fit. The goal of the modeling is to understand whether the additional transportation variables add explanatory power and the direction in which they are associated with well-being.

As a complement to our quantitative modeling, we conducted brief transportation case studies of the cities with the highest (Boulder, CO, USA) and lowest (Fort Smith, AR, USA) Gallup Healthways Well-Being Index scores. The goal was to understand how these cities are committing to sustainable transportation infrastructure in support of potentially enhancing residential happiness. First, we performed a thorough review of the sustainable transportation policies, master plans, and strategies for each city. Next, we conducted interviews with city employees to better understand future sustainable transportation plans. We selected potential interviewees by searching for transportation planners, urban planners, parks and recreation staff, and government officials on city websites, and recruited via phone and email. Ultimately, we received feedback from two municipal officials in each city. All interviews were completed via online and email correspondence. The purpose of these interviews was to supplement the quantitative study and publicly available information on the direction of the two cities from a sustainable transportation perspective. We asked four initial questions, focusing on aspects of alternative transportation modes from our quantitative analysis, to initiate an open-ended semi-structured interview process: 
(1) What are the future plans for expansion of pedestrian and bike infrastructure?

(2) What are the future plans for expansion of public transit?

(3) What are the future plans for automobile infrastructure?

(4) What are the public education programs you are currently implementing and plan on implementing in the future for promoting walking, biking and public transit?

\section{Results}

\subsection{Quantitative Models}

Table 2 summarizes the results for each regression model relating commute characteristics and economic predictors to subjective well-being. In all models, the economic predictors are intended primarily as controls so that the independent effect of commute time and mode share on happiness can be examined. Their potential multicollinearity does not affect the performance of our primary variables of interest; variance inflation factors for all commute time and mode share variables range from 1.7-2.3 across the models in our study.

Model 1 contains only the economic control variables and commute time. It shows that unemployment ratio, median age, educational level, the proportion of foreign born, and disability are significantly associated with regional happiness and that commute time has a negative but insignificant effect on regional happiness. The insignificance of this hypothesized relationship may have to do with the qualitative experience of different modes: an additional minute traveling by car has a different effect than an additional minute of walking, all else equal.

To test this hypothesis, we added commute mode share variables one at a time in subsequent models (Models 2-6). In general, explanatory power is increased when mode share is included as an explanatory variable, with greater coefficients of determination (ranging from 0.49-0.54) as compared to Model 1. The analysis of variance results show that each model with independent variables describing commute mode shares represents a significant improvement over Model 1, except that which includes public transportation mode share (Model 5). As expected, higher drive alone mode shares are associated with lower well-being scores (Model 2), while higher telecommute, carpool, and non-motorized mode shares are associated with higher well-being scores (Models 3, 4, and 6, respectively). 
Table 2. Multiple regression results.

\begin{tabular}{|c|c|c|c|c|c|c|c|c|c|c|c|c|}
\hline \multirow{3}{*}{ Variable } & \multicolumn{10}{|c|}{ Dependent Variable: Composite CBSA Happiness(Gallup-Healthways) } & & \\
\hline & \multicolumn{2}{|c|}{ Model 1} & \multicolumn{2}{|c|}{ Model 2} & \multicolumn{2}{|c|}{ Model 3} & \multicolumn{2}{|c|}{ Model 4} & \multicolumn{2}{|c|}{ Model 5} & \multicolumn{2}{|c|}{ Model 6} \\
\hline & Coeff. & t-Statistic & Coeff. & $\mathrm{t}$-Statistic & Coeff. & $\mathrm{t}$-Statistic & Coeff. & t-Statistic & Coeff. & t-Statistic & Coeff. & t-Statistic \\
\hline Constant & 54.2 & $4.06^{* * *}$ & 79.62 & $5.77^{* * *}$ & 63.49 & $4.93^{* * *}$ & 55.32 & $4.18^{* * *}$ & 56.30 & $4.12 * * *$ & 56.55 & $4.39 * * *$ \\
\hline Log (Median household income) & 2.13 & 1.56 & 1.35 & 1.03 & 1.51 & 1.15 & 1.51 & 1.09 & 2.09 & 1.53 & 2.62 & $1.98^{* *}$ \\
\hline Unemployment ratio & -18.86 & $-3.15^{* * *}$ & -18.67 & $-3.30 * * *$ & -23.25 & $-4.02 * * *$ & -18.52 & $-3.12 * * *$ & -18.40 & $-3.06 * * *$ & -18.78 & $-3.26 * * *$ \\
\hline Log(Median age) & -3.49 & $-2.09 * *$ & -3.10 & $-1.96 *$ & -4.84 & $-2.99 * * *$ & -2.63 & -1.54 & -3.45 & $-2.06^{* *}$ & -3.74 & $-2.32 * *$ \\
\hline Proportion foreign-born & 7.47 & $2.10^{* *}$ & 1.90 & 0.53 & 6.95 & $2.05^{* *}$ & 6.48 & $1.82 *$ & 6.55 & $1.74 *$ & 4.64 & 1.32 \\
\hline Proportion with greater than a high school education & 14.26 & $3.63^{* * *}$ & 9.14 & $2.36^{* *}$ & 10.18 & $2.64^{* * *}$ & 14.91 & $3.82 * * *$ & 13.41 & $3.27^{* * *}$ & 9.70 & $2.44^{* *}$ \\
\hline Proportion disabled & -23.97 & $-2.72 * * *$ & -29.92 & $-3.55^{* * *}$ & -17.12 & $-2.01 * *$ & -30.53 & $-3.29 * *$ & -24.70 & $-2.78 * * *$ & -22.62 & $-2.66^{* * *}$ \\
\hline Proportion renting & -3.44 & -1.17 & -6.45 & $-2.26^{* *}$ & -4.84 & $-1.78^{*}$ & -3.30 & -1.13 & -3.81 & -1.27 & -7.42 & $-2.44 * *$ \\
\hline Proportion with health insurance coverage & -4.87 & -1.26 & -4.65 & -1.27 & -0.30 & -0.08 & -3.45 & -0.89 & -5.59 & -1.40 & -8.25 & $-2.14 * *$ \\
\hline Commute time & -0.07 & -1.54 & -0.09 & $-2.08^{* *}$ & -0.06 & -1.37 & -0.08 & -1.55 & -0.09 & $-1.70 *$ & -0.05 & -1.03 \\
\hline Drive alone proportion & & & -14.40 & $-4.55^{* * *}$ & & & & & & & & \\
\hline Telecommute proportion & & & & & 42.20 & $4.29 * * *$ & & & & & & \\
\hline Carpool proportion & & & & & & & 14.62 & $2.06^{* *}$ & & & & \\
\hline Public transportation proportion & & & & & & & & & 5.21 & 0.75 & & \\
\hline Non-motorized proportion & \multirow{3}{*}{\multicolumn{2}{|c|}{0.49}} & \multirow{3}{*}{\multicolumn{2}{|c|}{$\begin{aligned} & 0.55 \\
F= & 20.74^{* * *}\end{aligned}$}} & \multirow{3}{*}{\multicolumn{2}{|c|}{$\begin{array}{c}0.54 \\
F=18.42 * * *\end{array}$}} & & & & & & $3.69^{* * *}$ \\
\hline Adjusted $\mathbf{R}^{2}$ & & & & & & & \multirow{2}{*}{\multicolumn{2}{|c|}{$\begin{array}{c}0.50 \\
F=4.26^{* *}\end{array}$}} & \multirow{2}{*}{\multicolumn{2}{|c|}{$\begin{array}{c}0.49 \\
F=0.56\end{array}$}} & \multirow{2}{*}{\multicolumn{2}{|c|}{$\begin{aligned} & 0.53 \\
F= & 13.65\end{aligned}$}} \\
\hline ANOVA w.r.t to Model 1 & & & & & & & & & & & & \\
\hline
\end{tabular}

Note: $\mathrm{N}=174$ for all models. Statistical significance indicated by asterisks: ${ }^{*} p<0.1,{ }^{* *} p<0.05,{ }^{* * *} p<0.01$. CBSA, core based statistical area. 


\subsection{Case Studies}

While quantitative analyses of associations between transportation measures and SWB are helpful, they do not necessarily provide deep insight into the complex processes governing human happiness and well-being. Therefore, we supplement these analyses with case studies of the highest and lowest scoring Gallup Healthways Well-Being Index cities. We first present descriptive statistics (Table 3) and the results from the review of existing publicly available resources, followed by the results of interviews with local transportation experts.

Table 3. Descriptive data for case study cities.

\begin{tabular}{cccccc}
\hline Case Study City & $\begin{array}{c}\text { Mean Temperatures } \\
\left({ }^{\circ} \text { F), January and July }\right.\end{array}$ & $\begin{array}{c}\text { Median } \\
\text { Income (\$) }\end{array}$ & $\begin{array}{c}\text { Unemployment } \\
\text { Rate (\%) }\end{array}$ & $\begin{array}{c}\text { Population Growth (\%), } \\
\text { April 2010-July 2016 }\end{array}$ & $\begin{array}{c}\text { Mean Commute } \\
\text { Time (min) }\end{array}$ \\
\hline $\begin{array}{c}\text { Boulder, } \\
\begin{array}{c}\text { Colorado } \\
\text { Fort Smith, } \\
\text { Arkansas }\end{array}\end{array}$ & $32.8,73.2$ & 56,312 & 6.63 & 9.4 & 21.7 \\
\hline
\end{tabular}

Boulder County, Colorado, is the highest scoring CBSA (WBI = 72.5), while the lowest scoring CBSA (WBI $=59.5)$ is Fort Smith, AR-OK. Boulder butts up against the Rocky Mountains $(5430 \mathrm{ft}$, $1655 \mathrm{~m}$ ), and various lakes, streams, and small hills dot the city. Fort Smith is located at a bend in the Arkansas River, in the Arkansas Valley at the southern extent of the Boston Mountain Plateau (463 ft, $141 \mathrm{~m}$ ) of the Ozark Mountains. Like Boulder, Fort Smith is dotted with lakes, streams, and hills, and the ruggedness of the adjacent terrain may limit urban expansion.

\subsection{Transportation Schemes}

Even with its altitude and topographic variety, Boulder is known to have a well-rounded transportation scheme. The city has its Community Transit Network (CTN), which are high frequency, branded transit services designed in partnership with the community. With $10 \mathrm{~min}$ or better frequencies, these are intended to be schedule-free as strong incentive to use the bus. The city program GO Boulder provides support for non-automobile modes through the Bicycle Living Laboratory: an initiative to experiment and pilot specific project designs that could be used more widely as part of their Complete Streets efforts to improve walking, biking and transit. Boulder has been a Bicycle Friendly Community since 2014, according to the League of American Bicyclists, with more than 90\% of Elementary and Middle School children receiving bicycle education. The city has an extensive and largely complete bike system including 80 underpasses and bike facilities on all major roads. Additionally, for all trips, nearly $20.3 \%$ of residents travel by bike and $17.7 \%$ by foot and, for the work commute, $35.3 \%$ by bike and $10 \%$ by foot [57].

The Fort Smith Transit Department's mission is to provide safe, efficient, affordable, prompt, friendly, professional, and clean public transportation to improve the quality of life for the citizens of Fort Smith, Arkansas. Like the City of Boulder, Fort Smith is focused on road improvement for automobiles [58], while also working to enhance sustainable alternatives. While current bikeways are open and clearly marked on neighborhood streets, future plans include both striped bicycle lanes on selected streets and bike paths that are separate from the road. In addition, the city's Fort Smith Trails and Greenways plan includes the creation of 88 miles of trails over a period of 15 years. These will be unpaved paths on the periphery of the city meant for recreation rather than transport.

\subsection{Ridership}

In 2015, Boulder's average local weekday ridership was 20,347, a 9.21\% increase from 2002 [59]. The city plans to add a bus rapid transit system with dedicated lanes for buses as well as supportive adaptations for carpools, vanpools, electric bikes, a guaranteed ride home program, and car sharing. Around $22 \%$ of the population carpools for all rides, while single occupancy vehicles only constitute 
$36 \%$ of all trips. Maps, subsidies, and contact numbers for all these transportation modes are provided through the Go Boulder website. The city of Boulder has incorporated sustainability as one of the primary features in its transit system, and the city's high well-being score may be an outcome of these efforts [60]. Fort Smith's daily public transit ridership is approximately 565, or $0.06 \%$ of the population [58]. The population density in Fort Smith is approximately 1400 people per square mile, less than half that of Boulder. The Transit Department, however, is focused on increasing its ridership by developing a new intermodal terminal and by increasing the number of shelters along bus routes.

\subsection{Interview Results}

The City of Boulder's employees provided insight on the city's future plans for sustainable transportation, mostly with respect to the Transportation Master Plan (TMP). Four themes emerged as a result of the interview: (1) pedestrian and bike infrastructure; (2) public transit; (3) automobile infrastructure; and (4) public education programs. Improvements to enhance the quality of pedestrian and bike infrastructure are the first priority. The city also conducted a low stress network analysis, and is working on a Bike 2.0 system that would be attractive to concerned cyclists. With respect to public transit, the TMP called for a Renewed Vision for Transit, which aims to enhance high frequency services within the community and Bus Rapid Transit (BRT) connections between communities. The top investment priority within automobile infrastructure, however, is the safety and maintenance of the existing system, with a majority of that spending going to the road system. Detailed information can be found in the 28 August 2015 Study Session packet. The city also intends to improve the Intelligent Transportation System (ITS) aspects of the system, but the TMP does not support adding road capacity. Finally, with respect to public education programs, Boulder is integrating education programs such as 'SafeStreets', which spread safety information to prevent motor vehicle collisions with pedestrians and bikers. In addition, the 'Way of the Path' program aims to improve the safety and experience of people using Boulder's multi-use paths by raising awareness of path etiquette and rules. Further information on the recent and existing programs can be found on the wwww.GOBoulder.net [61] web site under Plans and Programs.

The City of Fort Smith's personnel provided insight on the direction of their sustainable transportation networks. Three themes emerged as a result of the interview: (1) pedestrian and bike infrastructure; (2) general public transit services expansion; and (3) public education programs. Considering pedestrian and bike infrastructure, the City of Fort Smith uses several committees to develop and educate citizens about the trail system planned for the area. These individuals research the benefits of the system, and conduct outreach through public meetings, social media, articles, and public speaking, television, and newspaper articles. Health benefits, tourism potential, and new transportation opportunities are viewed as important facets of non-motorized vehicles. The City would like to provide safe routes as alternative avenues for families, especially children traveling to school and parks, with zero or limited interaction with traffic. Fort Smith is a large community with very busy streets; the trail system will help put parents' minds at ease.

Fort Smith Transit works closely with the Frontier Metropolitan Planning Organization (MPO) to research opportunities for general public transit services expansion. The Frontier MPO includes a website with the latest information pertaining to the transit department's outreach efforts to expand services into the metropolitan area. Forth Smith is also striving to improve the quality of life and health of its residents through public education programs. From an economic standpoint, the goal is city growth. Attracting new citizens with new jobs, affordable housing, good schools, and recreation venues (e.g., parks and trails) are the key to that growth process. Despite the challenges, the municipality is focused on making the city a place where everyone wants to live, work, and play. Finally, Fort Smith residents seem to support this approach, as voters approved a one-eighth percent sales tax increase to support the trails program and park system. 


\section{Discussion}

The general pattern of results indicates that regions that favor sustainable commute mode shares over driving-alone have higher well-being scores, even when controlling for important economic predictors of happiness. These results suggest that transportation policies that increase the use of sustainable modes may have implications for population-wide happiness and well-being, consistent with the literature review. The results should not be interpreted to mean that, at the individual level, automobile ownership is not associated with increases in quality of life. The data specifically speak to the commute experience. Automobile ownership and use carries with it a number of benefits that are completely separate from the journey to work and should be investigated separately.

As mentioned in the methods section, our results draw on data from a non-random sample of 187 out of approximately 1000 CBSAs across the United States. Our data represent only those CBSAs which have complete happiness observations from the Gallup Healthways Well-being Index. The results, however, do bear several implications to be considered with respect to regional happiness and transportation planning. The relationship requires more investigation with a larger number of complete CBSA observations, but potential associations could be linked to the positive influences that come from non-motorized mode use and carpooling (e.g., improved air quality, stronger social connections, reduced congestion and stress, reduced vehicle wear and tear) [62].

The telecommute mode share is also significantly and positively associated with self-reported happiness. The results suggest that the larger the percentage of employees who work from home, the higher self-reported happiness will be in a region. Potential positive influences from working remotely might include the elimination of a commute, flexibility in schedule, improved working spaces, better work-life balance, and freedom from routine [28]. Moreover, the experience provides greater job related well-being and lower incidences of associated negative job effects on health [30]. However, future studies should look more closely at the relationship between the telecommuting and happiness variables.

Across all modes, the model results demonstrate that mode shares are more consistently linked to well-being than commute time, suggesting that the commute's quality matters more than time. Once mode is controlled, the results are suggestive that shorter commutes result in greater regional well-being. The inconsistent nature of the commute time variable may be due to the types of commutes that are supported in dense vs. sprawling environments. In dense urban areas, non-motorized commutes are likely to be short and convenient, but commuting by car will tend to be long and onerous due to traffic congestion. On the other hand, sprawling areas may experience quick automobile commutes, but relatively long non-motorized journeys to work. Mean commute times may be similar in both locations, but well-being outcomes could be dramatically different. Controlling for commute mode allows the true nature of the relationship between time, mode, and happiness to be revealed.

The modeling results also provide some insight for strategies or policies that might be employed at the state level with respect to our current transportation systems. First, policy can support, provide, and encourage the use of alternative modes of transit to work. Some states have encouraged carpooling through the use of high occupancy vehicle (HOV) lanes, and shared park and ride facilities, but methods of increasing the percentage of shared trips continue to be investigated and developed [63]. This present study shows that realized benefits are potentially not only environmental or economic in nature.

Additionally, states might consider offering greater access to public transit for the work commute within their urban centers. However, within areas outside of urban centers, public transit is often considered less economically efficient [64], and may therefore be difficult to develop, especially for less densely populated areas. State governments could also offer businesses and residents financial incentives (tax breaks, rebates etc.) to encourage telecommuting and working from home. Finally, those states that self-report low happiness might consider offering incentives that encourage reduced commute times or provide residents with more flexibility in how and when they reach their places of employment. 
The illustrative case studies in our research provide further discussion points. Boulder and Fort Smith differ in income levels and transportation networks, which are associated with differences in self-reported well-being. Differences exist in the amount of public transit, walking, and biking infrastructure, and the extent of cultural integration of using these modes of transport. Infrastructure must be in place to develop a sustainable transportation system, which enables public transit, walking, and biking as primary travel modes. Boulder meets this criterion. Yet, both Boulder and Forth Smith are are working to provide alternative modes of transportation to enhance the quality of life for their residents.

From a walking and biking standpoint, Boulder is better connected; though Fort Smith is dedicated to expanding access through mostly unpaved routes that may improve well-being by offering residents a place to recreate and walk [65], as spending time outdoors improves well-being [66] through indirect health benefits [67]. Boulder residents walk and bike at higher rates, supported by greater infrastructure and proximity to outdoor recreation areas. Fort Smith has shorter commute times than Boulder, but the majority of Fort Smith residents drive alone compared to nearly $20 \%$ of the population in Boulder that carpools. Variations in these two cities, with respect to transportation, certainly might play a role in the SWB of residents.

Ultimately, our quantitative analyses demonstrate that more sustainable transportation modes are associated with higher self-reported happiness. Our case study analyses of Boulder and Fort Smith, coupled with interviews of city officials, shows that there is a sustainable transportation mindset in each city. Boulder is further along in its development and implementation of sustainable transportation, with a well-established infrastructure that supports alternative modes of transit, commuting, and recreating for its residents. The findings, however, are likely related to the current economic standing and density of Boulder. The case study of Fort Smith shows encouragingly how cities with lower levels of sustainable transportation infrastructure are striving to improve while meeting the challenge of economic growth. Our work is an attempt to build more evidence for the connections between our built environment and human well-being. While the study is rooted in a cross-sectional analysis from which causation cannot be drawn, it bolsters prior evidence that we ought to consider the implications of urban design on residents' happiness.

\section{Conclusions}

The pursuit of happiness matters to all humans; the evidence presented in this study supports the notion that commute mode might affect this pursuit. This study is based on the hypothesis that aspects of sustainable US transportation commute modes and city-level measures of happiness are associated. Specifically, we considered five commute measures in US cities as predictors of happiness: the percent of residents who drive alone, telecommute, carpool, use public transport, and use non-motorized modes. Our results indicate that the five commute mode measures predict nearly $53 \%$ of the variability in city-level happiness, when controlling for income, commute time, and other predictors. Our case studies of U.S. cities with the highest (Boulder, CO, USA) and lowest (Fort Smith, AR, USA) well-being scores gives insight into some potential factors that might be associated from a transportation perspective. Yet, both cities are committed to providing sustainable modes of transportation to their residents which, in turn, may enhance regional happiness.

Our quantitative analysis is limited by its cross-sectional design and its use of only a single year of data. As the available dependent variable data were from 2009, the well-being index was potentially affected by unobserved factors (unrelated to transportation) related to the 2007-2008 financial crisis. Further, some communities may have been more resilient to the financial crisis (e.g., Boulder, CO, USA), reporting higher levels of wellbeing than those significantly affected communities. As with all cross-sectional studies, the variation across the dataset comes from already existing differences between observations. This means that the results represent correlations, rather than causal effects. Still, they contribute to our understanding of the potential benefits of reduced automobile dependence. Further work should examine whether the results hold at the individual level and should include 
additional years of data to determine whether areas that see changes in commute mode shares see corresponding changes in well-being. The case studies within our research could also benefit from more in-depth investigation in future studies.

Overall, our study indicates support for city-level incentives and policies that promote greater carpooling participation, access to public transit for the work commute, and more opportunities to work from home. U.S. cities will continue to grow, and will serve as home to the majority of our population. Thus, we must determine the most effective methods of moving our people from place to place. Human well-being may benefit from alternative commute modes (or the elimination of the commute altogether), and governments and planning agencies can support these choices with infrastructure and land use planning. A sustainable transportation system focused on quality commutes can support residents in pursuing their happiness, while promoting a sustainable future for our planet, economy, society, and diverse cultures.

Acknowledgments: The authors would like to acknowledge the contributions of Adam Gabriele and Natalia Rodriguez. The two strengthened the quality of our work by editing and ensuring we met the expectations of our case study cities. Thank you!

Author Contributions: Scott Cloutier contributed to and organized the literature review, paper organization and synthesis, and assisted with data collection and analysis. He also wrote discussions related to sustainability and happiness and organized and synthesized the works of the contributing authors. Alex Karner, Parinaz Toufani, and Nuri Onat contributed to the literature review, acquired data and conducted analyses and synthesized the results. Alex Karner also contributed to writing in all areas of the paper, drawing on his expertise in sustainable transportation systems. Hanna L. Breetz provided critical analyses of the paper, along with contributions on the qualitative versus quantitative aspects of our study. Sambhram Patel and Siddhanth Paralkar assisted with the literature review and conducted research and interviews for the respective case study cities. Erica Berejnoi, Beth Ann Morrison, Jason Papenfuss, A. Davieau Briggs, and Cynthia Carlson all assisted with research and writing within various areas of the paper. All authors contributed to each section of the paper at different degrees.

Conflicts of Interest: The authors declare no conflict of interest.

\section{References}

1. Gärling, T.; Ettema, D.; Friman, M. Handbook of Sustainable Travel; Springer: Berlin, Germany, 2013.

2. Morris, E.A. Access and Outcomes: Transportation, Location, and Subjective Well-Being; UC Berkeley Transportation Library: Berkeley, CA, USA, 2011; Volume 73.

3. Morris, E.A.; Guerra, E. Mood and mode: Does how we travel affect how we feel? Transportation 2015, 42, 25-43. [CrossRef]

4. Gallup. Gallup Healthways Wellbeing Index. Available online: http://www.well-beingindex.com/ (accessed on 18 June 2017).

5. Zipperer, W.C.; Pickett, S.T. Urban ecology: Patterns of population growth and ecological effects. eLS 2012. [CrossRef]

6. United Nations Development Programme. Available online: http://www.undp.org/content/undp/en/ home.html (accessed on 18 June 2017).

7. Montgomery, C. Happy City: Transforming Our Lives through Urban Design; Macmillan: London, UK, 2013.

8. Cloutier, S.; Larson, L.; Jambeck, J. Are sustainable cities "happy” cities? Associations between sustainable development and human well-being in urban areas of the United States. Environ. Dev. Sustain. 2014, 16, 633-647.

9. Florida, R.; Mellander, C.; Rentfrow, P.J. The happiness of cities. Reg. Stud. 2013, 47, 613-627. [CrossRef]

10. Leyden, K.M.; Goldberg, A.; Michelbach, P. Understanding the pursuit of happiness in ten major cities. Urban Aff. Rev. 2011, 47, 861-888. [CrossRef]

11. Pfeiffer, D.; Cloutier, S. Planning for happy neighborhoods. J. Am. Plan. Assoc. 2016, 82, 267-279. [CrossRef]

12. Abou-Zeid, M.; Witter, R.; Bierlaire, M.; Kaufmann, V.; Ben-Akiva, M. Happiness and travel mode switching: Findings from a swiss public transportation experiment. Transp. Policy 2012, 19, 93-104. [CrossRef]

13. Cloutier, S.; Pfeiffer, D. Sustainability through happiness: A framework for sustainable development. Sustain. Dev. 2015, 23, 317-327. [CrossRef]

14. Duarte, A.; Garcia, C.; Giannarakis, G.; Limão, S.; Polydoropoulou, A.; Litinas, N. New approaches in transportation planning: Happiness and transport economics. Netnomics 2010, 11, 5-32. [CrossRef] 
15. Ettema, D.; Gärling, T.; Olsson, L.E.; Friman, M.; Moerdijk, S. The road to happiness: Measuring Dutch car drivers' satisfaction with travel. Transp. Policy 2013, 27, 171-178. [CrossRef]

16. Krueger, A.B.; Kahneman, D.; Fischler, C.; Schkade, D.; Schwarz, N.; Stone, A.A. Time use and subjective well-being in france and the us. Soc. Indic. Res. 2009, 93, 7-18. [CrossRef]

17. Olsson, L.E.; Gärling, T.; Ettema, D.; Friman, M.; Fujii, S. Happiness and satisfaction with work commute. Soc. Indic. Res. 2013, 111, 255-263. [CrossRef] [PubMed]

18. Stutzer, A.; Frey, B.S. Stress that doesn't pay: The commuting paradox. Scand. J. Econ. 2008, 110, 339-366. [CrossRef]

19. Zhao, J.; Lee, J. Experience or Memory: Happiness of Commuting. In Proceedings of the 92nd Annual Meeting on Transportation Research Board, Washington, DC, USA, 3-17 January 2013.

20. Abou-Zeid, M.; Ben-Akiva, M. Well-being and activity-based models. Transportation 2012, 39, $1189-1207$. [CrossRef]

21. Deutsch-Burgner, K.; Ravualaparthy, S.; Goulias, K. Place happiness: Its constituents and the influence of emotions and subjective importance on activity type and destination choice. Transportation 2014, 41, 1323-1340. [CrossRef]

22. Martin, A.; Goryakin, Y.; Suhrcke, M. Does active commuting improve psychological wellbeing? Longitudinal evidence from eighteen waves of the British household panel survey. Prev. Med. 2014, 69, 296-303. [PubMed]

23. Smith, O.B. Peak of the Day or the Daily Grind: Commuting and Subjective Well-Being. Ph.D. Dissertation, Portland State University, Portland, OR, USA, 2013.

24. Mytton, O.T.; Panter, J.; Ogilvie, D. Longitudinal associations of active commuting with wellbeing and sickness absence. Prev. Med. 2016, 84, 19-26. [CrossRef] [PubMed]

25. Hansson, E.; Mattisson, K.; Björk, J.; Östergren, P.-O.; Jakobsson, K. Relationship between commuting and health outcomes in a cross-sectional population survey in Southern Sweden. BMC Public Health 2011, 11, 834. [CrossRef] [PubMed]

26. Dora, C.; Phillips, M. Transport, Environment and Health; WHO Regional Office Europe: Copenhagen, Denmark, 2000.

27. Breaugh, J.A.; Farabee, A.M. Telecommuting and flexible work hours: Alternative work arrangements that can improve the quality of work life. In Work and Quality of Life; Springer: Berlin, Germany, 2012; pp. 251-274.

28. Hill, E.J.; Fellows, K.J. Telecommuting. In Encyclopedia of Quality of Life and Well-Being Research; Springer: Berlin, Germany, 2014; pp. 6599-6600.

29. Kelloway, E.; Gottlieb, B. The effect of alternative work arrangements on women's well-being: A demand-control model. Women's Health 1997, 4, 1-18.

30. Anderson, A.J.; Kaplan, S.A.; Vega, R.P. The impact of telework on emotional experience: When, and for whom, does telework improve daily affective well-being? Eur. J. Work Organ. Psychol. 2015, 24, 882-897. [CrossRef]

31. Crabtree, S.; Index, G.-H.W.-B. Wellbeing Lower among Workers with Long Commutes. Available online: http://www.gallup.com/poll/142142/wellbeing-lower-among-workers-long-commutes.aspx (accessed on 18 June 2017).

32. Lawless, N.M.; Lucas, R.E. Predictors of regional well-being: A county level analysis. Soc. Indic. Res. 2011, 101, 341-357. [CrossRef]

33. Bodea, T.D.; Garrow, L.A.; Meyer, M.D.; Ross, C.L. Socio-demographic and built environment influences on the odds of being overweight or obese: The Atlanta experience. Transp. Res. Part A Policy Pract. 2009, 43, 430-444. [CrossRef]

34. National Center on Health, P.A.a.D.N. Sedentary Lifestyle Is Dangerous to Your Health. N.D. Available online: http:/ / www.nchpad.org/403/2216/Sedentary Lifestyle is Dangerous to Your Health (accessed on 18 June 2017).

35. Frank, L.D.; Schmid, T.L.; Sallis, J.F.; Chapman, J.; Saelens, B.E. Linking objectively measured physical activity with objectively measured urban form: Findings from Smartraq. Am. J. Prev. Med. 2005, 28, 117-125. [CrossRef] [PubMed]

36. King, A.C.; Sallis, J.F.; Frank, L.D.; Saelens, B.E.; Cain, K.; Conway, T.L.; Chapman, J.E.; Ahn, D.K.; Kerr, J. Aging in neighborhoods differing in walkability and income: Associations with physical activity and obesity in older adults. Soc. Sci. Med. 2011, 73, 1525-1533. [CrossRef] [PubMed] 
37. Ussher, M.H.; Owen, C.G.; Cook, D.G.; Whincup, P.H. The relationship between physical activity, sedentary behaviour and psychological wellbeing among adolescents. Soc. Psychiatry Psychiatr. Epidemiol. 2007, 42, 851-856. [CrossRef] [PubMed]

38. Ogilvie, D.; Mitchell, R.; Mutrie, N.; Petticrew, M.; Platt, S. Shoe leather epidemiology: Active travel and transport infrastructure in the urban landscape. Int. J. Behav. Nutr. Phys. Activ. 2010, 7, 43. [CrossRef] [PubMed]

39. Quickfacts. Available online: https://www.census.gov/quickfacts/ (accessed on 19 June 2017).

40. Dilger, R.J. Istea: A new direction for transportation policy. Publ. J. Fed. 1992, 22, 67-78. [CrossRef]

41. Handy, S. Regional transportation planning in the US: An examination of changes in technical aspects of the planning process in response to changing goals. Transp. Policy 2008, 15, 113-126. [CrossRef]

42. Sears, L.E.; Agrawal, S.; Sidney, J.A.; Castle, P.H.; Rula, E.Y.; Coberley, C.R.; Witters, D.; Pope, J.E.; Harter, J.K. The well-being 5: Development and validation of a diagnostic instrument to improve population well-being. Popul. Health Manag. 2014, 17, 357-365. [CrossRef] [PubMed]

43. Gallup, A.M.; Newport, F. The Gallup Poll: Public Opinion 2009; Rowman \& Littlefield Publishers: Lanham, MD, USA, 2010.

44. Kahneman, D.; Deaton, A. High income improves evaluation of life but not emotional well-being. Proc. Natl. Acad. Sci. USA 2010, 107, 16489-16493. [CrossRef] [PubMed]

45. Rentfrow, P.J.; Mellander, C.; Florida, R. Happy states of America: A state-level analysis of psychological, economic, and social well-being. J. Res. Personal. 2009, 43, 1073-1082. [CrossRef]

46. Bjørnskov, C. Social capital and happiness in the United States. Appl. Res. Qual. Life 2008, 3, 43-62. [CrossRef]

47. Easterlin, R.A. Income and happiness: Towards a unified theory. Econ. J. 2001, 111, 465-484. [CrossRef]

48. Easterlin, R.A.; McVey, L.A.; Switek, M.; Sawangfa, O.; Zweig, J.S. The happiness-income paradox revisited. Proc. Natl. Acad. Sci. USA 2010, 107, 22463-22468. [CrossRef] [PubMed]

49. Diaz-Serrano, L. Disentangling the housing satisfaction puzzle: Does homeownership really matter? J. Econ. Psychol. 2009, 30, 745-755. [CrossRef]

50. Gimenez-Nadal, J.I.; Molina, J.A. Regional unemployment, gender, and time allocation of the unemployed. Rev. Econ. Househ. 2014, 12, 105-127. [CrossRef]

51. Clark, A.; Knabe, A.; Rätzel, S. Boon or bane? Others' unemployment, well-being and job insecurity. Labour Econ. 2010, 17, 52-61.

52. Layard, P.R.G.; Layard, R.; Nickell, S.J.; Jackman, R. Unemployment: Macroeconomic Performance and the Labour Market; Oxford University Press on Demand: Oxford, UK, 2005.

53. Leiserowitz, A.A.; Kates, R.W.; Parris, T.M. Sustainability values, attitudes, and behaviors: A review of multinational and global trends. Annu. Rev. Environ. Resour. 2006, 31, 413-444. [CrossRef]

54. Cuñado, J.; de Gracia, F.P. Does education affect happiness? Evidence for spain. Soc. Indic. Res. 2012, 108, 185-196. [CrossRef]

55. Helliwell, J.F.; Bonikowska, A.; Shiplett, H. Migration as a Test of the Happiness Set Point Hypothesis: Evidence from Immigration to Canada; National Bureau of Economic Research: Cambridge, MA, USA, 2016.

56. Graham, C. Happiness and health: Lessons-And questions-For public policy. Health Aff. 2008, $27,72-87$. [CrossRef] [PubMed]

57. Mode Shift Report. Available online: https://www-static.bouldercolorado.gov/docs/2016_Transportation Report_on_Progress-1-201603181433.pdf (accessed on 18 June 2017).

58. Western Arkansas Planning and Development District. Available online: http://www.wapdd.org (accessed on 18 June 2017).

59. The Transportation Report on Progress. Available online: https://bouldercolorado.gov/transportation/ 2016-report-on-progress (accessed on 18 June 2017).

60. State of the System Report. 2013. Available online: https://www-static.bouldercolorado.gov/docs/ BOULDER_TMP-SOS_Final_Rept_COMP-1-201311011558.pdf (accessed on 18 June 2017).

61. Transportation Information System. Available online: https://bouldercolorado.gov/goboulder/bus (accessed on 18 June 2017).

62. Russell, M.L. Travel Time Use on Public Transport: What Passengers Do and how It Affects Their Wellbeing. Ph.D. Thesis, University of Otago, Dunedin, New Zealand, 2012.

63. Furuhata, M.; Dessouky, M.; Ordóñez, F.; Brunet, M.-E.; Wang, X.; Koenig, S. Ridesharing: The state-of-the-art and future directions. Transp. Res. Part B Methodol. 2013, 57, 28-46. [CrossRef] 
64. Litman, T. Evaluating Public Transit Benefits and Costs; Victoria Transport Policy Institute: Victoria, BC, Canada, 2015.

65. Ettema, D.; Smajic, I. Walking, places and wellbeing. Geogr. J. 2015, 181, 102-109. [CrossRef]

66. Parker, S.; Holland, W. Physical activity-a health and wellbeing priority. Australas. Parks Leisure 2014, 17, 45.

67. Steptoe, A.; Deaton, A.; Stone, A.A. Subjective wellbeing, health, and ageing. Lancet 2015, 385, $640-648$. [CrossRef]

(c)

(C) 2017 by the authors. Licensee MDPI, Basel, Switzerland. This article is an open access article distributed under the terms and conditions of the Creative Commons Attribution (CC BY) license (http://creativecommons.org/licenses/by/4.0/). 